\title{
Overview of Research and Development for Anticancer Drugs
}

\author{
Junjie Xu1, Wenwei Mao ${ }^{2,3^{*}}$ \\ ${ }^{1}$ Shanghai Jiao Tong University School of Medicine, Shanghai, China \\ ${ }^{2}$ Lab of Microbial and Biochemical Pharmaceutical, School of Pharmacy, Shanghai Jiao Tong University, Shanghai, China \\ ${ }^{3}$ Engineering Research Center of Cell and Therapeutic Antibody, Ministry of Education, School of Pharmacy, Shanghai Jiao Tong \\ University, Shanghai, China \\ Email: ${ }^{*}$ wwmao@sjtu.edu.cn
}

How to cite this paper: $\mathrm{Xu}, \mathrm{J} . J$. and Mao, W.W. (2016) Overview of Research and Development for Anticancer Drugs. Journai of Cancer Therapy, 7, 762-772. http://dx.doi.org/10.4236/jct.2016.710077

Received: September 24, 2016

Accepted: October 18, 2016

Published: October 21, 2016

Copyright $\odot 2016$ by authors and Scientific Research Publishing Inc. This work is licensed under the Creative Commons Attribution International License (CC BY 4.0).

http://creativecommons.org/licenses/by/4.0/ (c) (i) Open Access

\begin{abstract}
Anticancer drugs research and development have been the largest market area in the pharmaceutical industry in terms of the number of project, clinical trials and spending. In the last 10 - 30 years, targeting therapy for cancers has been developed and achieved enormous clinical effectiveness by transforming some previously deadly malignancies into chronically manageable conditions, but cure problem still remains. This mini review outlined the current status of anticancer drugs development and hinted the opinions of how to further increase the accuracy and efficacy of discovery for cancer treatment.
\end{abstract}

\section{Keywords}

Anticancer Drugs, Research and Development, Target Therapy, Phenotype Targeting, Anti-Tumor Immunity

\section{Introduction}

Cancer is one of the leading causes of human death which is estimated at 8.2 million and will likely rise to 13 million worldwide per year till 2030 [1], and oncology has become the largest therapeutic area in the pharmaceutical industry in terms of the number of project, clinical trials and research and development spending [2]. Although in the past decade, there is an explosion in our understanding of cancer biology with many new potential disease targets, the ability to translate these advances into therapies is poor, with a failure rate approaching $90 \%$. As declining of expenditure on research and development by pharmaceutical companies while rising of the cost of bringing a new molecular entity to market, the so-called "Valley of Death" in anticancer drug de- 
velopment becomes a highly complex problem [3]. In this mini review, the curiosity-driven research coupled with rigorous preclinical and clinical drug discovery practices used in industry is outlined and opinion of how to increase the accuracy and efficacy of anticancer drug discovery is suggested.

\section{Anticancer Drugs Developed from Chemotherapy to Targeted Therapies}

For over 50 years, the search for anticancer drugs has been governed by the fact that tumor cells replicate more rapidly than normal cells and that DNA is the most important molecule in cell division. As a result, DNA is often the therapeutic target of anticancer drugs, and the vast majority of the currently used drugs cause DNA damage, interrupting cell division and subsequently causing cell death [4]. But in the last $10-30$ years, a new era of cancer therapy has emerged, with the treatment of cancers moving away from the use of cytotoxic drugs and nonspecific chemotherapy to chronic oral treatment with targeted molecular therapies [5]. Tamoxifen, selectively modulates oestrogen receptors, is considered as the first example of an oral "targeted" anticancer therapy since it was introduced into the clinic some 30 years ago and the introduction of rituximab for B cell lymphoma in the late 1990s inaugurated a new era of cancer therapy showcasing mAbs [5] [6].

The knowledge of several functional molecular and biological traits that distinguish tumor cells from normal cells, known as the hallmarks of cancer, has led to new and modern therapeutic approaches against this disease. Most cancer drugs are deliberately developed for specific molecular targets that involve these hallmarks. There are ten distinct characteristics of cancer cells that result in tumor growth and metastasis including: sustaining proliferative signaling, evading growth suppressors, resisting cell death, enabling replicative immortality, activating invasion and metastasis, and inducing angiogenesis, genome instability and mutation, deregulating cellular energetics, tumorpromoting inflammation, and avoiding immune destruction [4]. Based on these hallmarks of target discovery, a significant amount of biopharmaceuticals, such as small molecules, monoclonal antibodies and non-antibody proteins have been developed and applied to treat various cancers [2] [7]. At present, over 200 anticancer biopharmaeuticals have been approved, with many more at various stages of preclinical development, or clinical Phase I and II trials [2] [8] [9]. All these drugs constitute vivid examples of the emerging field of personalised medicine, with the potential to be used in cancer patients either as single agents or in combination therapy which are now revolutionising cancer treatment by transforming some previously deadly malignancies into chronically manageable conditions. Nevertheless, primary or secondary drug resistance, persistence of cancer stem cells and drug adverse effects still limit their ability to stabilise or cure malignant diseases in the long term [5]. Though oral administration of these drugs is associated with a better quality of life but poor tolerability and therapeutic failure are not uncommon, and relapse is a nearly inevitable consequence of treatment interruption [5]. Moreover, this shift to targeted agents is creating new paradigms in cancer 
care, with drug adherence becoming a more critical issue with increased numbers of oral chemotherapeutics [5] [10].

The mechanism of drug resistance in targeted therapy of cancer is broadly and deeply associated with tumor heterogeneity and may be involved in selective pressure provided by therapy [11], for example, targeted therapy with B-Raf serine/threonine-protein kinase, anaplastic lymphoma kinase or epidermal growth factor receptor kinase inhibitors induces a complex network of secreted signals in drug-stressed human and mouse melanoma and human lung adenocarcinoma cells. This therapy-induced secretome stimulates the outgrowth, dissemination and metastasis of drug-resistant cancer cell clones and supports the survival of drug-sensitive cancer cells, contributing to incomplete tumour regression [10]. Another example is that: a patient with metastatic breast cancer bearing an activating phosphatidylinositol-4,5-bisphosphate 3-kinase catalytic subunit alpha mutation was treated with its inhibitor BYL719, which achieved a lasting clinical response, but the patient was eventually became resistant to this drug and died shortly thereafter; a rapid autopsy was performed and found that all metastatic lesions, when compared to the pre-treatment tumor, had a copy loss of phosphatase and tensin homo$\log$ and those lesions that became refractory to BYL719 had additional and different phosphatase and tensin homolog genetic alterations, resulting in the loss of phosphatase and tensin homolog expression [11].

It is very important for translational studies of targeted agents to have the potential to produce more clinically relevant data not only to guide "go/no-go" decisions but also to investigate resistance pathways and rational drug combinations [12] [13]. Current efforts to understand resistance often center on two different strategies. One approach is to model the development of resistance in vitro using sensitive cell line models that are exposed to a specific targeted therapy until resistance emerges [14]. A second approach focuses on the genetic analyses of resistant biopsies to identify new genetic anomalies that could be driving resistance [15]. Successful use of anticancer designer drugs is likely to depend on simultaneous combinations of these drugs to minimize the development of resistant cancer cells. Considering the knowledge base of cancer signaling pathways, mechanisms of designer drug resistance should be anticipated, and early clinical trials could be designed to include arms that combine new drugs specifically with currently US Food and Drug Administration-approved drugs expected to blunt alternative signaling pathways which can be assessed at http://www.alternativesignalingpathways.com, and a software was developed to systematically identify signaling pathways that could facilitate resistance to drugs targeting a particular protein. This prototype software will inspire routine considerations of combining drugs in clinical trials in a way that anticipates designer drug resistance [16].

\section{Anticancer Drugs Developed from Targeting Redox Balance of Cancer Cells}

The role of redox signaling in cancer progression is well accepted. In general, a higher 
level of reactive oxygen species (ROS) is essential for cancer cell survival, proliferation, and metastasis via the regulation of redox signaling [17]. ROS are usually defined as oxygen-containing chemical species with high reactive properties and include superoxide anion, hydrogen radical, and nonradical molecules such as hydrogen peroxide. ROS were initially considered harmful to cells due to their interaction with, and irreversible damage to, biomolecules, e.g., proteins, lipids, and nucleic acids. Nonetheless, ROS can function as second messengers of signaling transduction in cellular physiology and cell stress responses, and can regulate multiple cancer related signaling pathways via reversible oxidative posttranslational modifications of cysteine in key redox-sensitive proteins, which leads to the structural and functional change of these proteins [18]. This indicates that ROS are in a certain central node of complex signaling networks inside a cell and altered redox regulation is a general phenotype of many cancers and has a crucial role in cancer etiology, progression and metastasis, targeting the cancer phenotype using a inducing/reducing cellular ROS level approach or targeting redox sensors involved in cancer may tackle the problem of intra-tumor heterogeneity and be more widely applicable to a range of tumors [19]. Therefore these therapeutic strategies comparing with targeting the genetic defects hold great potential to develop new approaches for anticancer treatment because targeting genetic defects in a personalized strategy is limited by the high degree of intra-tumor heterogeneity, adaptation of genetic networks and high somatic mutation rates in cancer. However, due to the complex delicate redox balance, i.e., ROS can serve useful and protective functions at low levels and harmful and destructive functions at high levels, the therapeutic targeting cellular redox pathways for cancer therapy need to be highly selective. Thus, the development of redox-active nanomaterials is an interesting approach to improve selectivity and outcome of cancer treatments [20]-[23].

Currently there are two promising strategies of research and development involved in targeting ROS inducing/reducing or related pathways. The one is to target the function of endoplasmic reticulum (ER) where eukaryotic cells fold and assemble membrane and secreted proteins before delivery to other cellular compartments or the extracellular environment [24]-[26]. Correctly folded proteins are released from the ER, and poorly folded proteins are retained until they achieve stable conformations; irreparably misfolded proteins are targeted for degradation. Increased ROS in cancer cells can overwhelm ER protein quality control, leading to misfolded protein buildup, causing ER stress. To cope with ER stress, eukaryotic cells activate the unfolded protein response to facilitate cancer proliferation by increasing levels of ER protein-folding enzymes and chaperones, enhancing the degradation of misfolded proteins, and reducing protein translation, thus targeting these ER hosted dynamic signaling network can lead increase or decrease of ROS levels in cancer cells and thereby influence overall cell fate [27]. These ER targets include inositol-requiring enzyme-1, protein kinase R-like endoplasmic reticulum kinase, and activating transcription factor-6 [26], glucose-regulated proteins [28] [29], heat shock proteins [29]-[31], endoplasmic reticulum disulfide oxidase [32] [33], peroxiredxins and glutathione peroxidases [34]. Efforts to develop 
small-molecule inhibitors, or monoclonal antibody/non-antibody proteins/vaccines targeting to these targets are underway, several of which have shown high potency and as well as selectivity in preclinical or clinical trials [27] [35].

The second strategy is to target perturbation of glycolysis and oxidative phosphorylation in cancer cells. Nearly a hundred years of scientific research has revealed that cancer cells rewire their metabolism and prefer to utilize aerobic glycolysis rather than mitochondrial oxidative phosphorylation for glucose-dependent ATP production, which is thought to generate high intracellular levels of lactate and reactive oxygen species (ROS) [36] [37]. The detoxification of these accumulating metabolites and the equilibrium between reduced and oxidized nicotine adenine dinucleotide are two prominent mechanisms regulating redox status and hence energy homeostasis in tumors. Targeting both processes may thus be selectively cytotoxic for cancer cells [37]. Multiple glycolytic targets related to this complex biochemical process has been studied and under developing including lactate dehydrogenase which catalyzes the reduction of pyruvate by reduced nicotinamide adenine dinucleotide to form lactate [38] [39], poly (ADPribose) polymerases which utilize oxidized nicontinamide adenine dinucleotide as a substrate to catalyze the attachment of ADP-ribose polymers to target proteins [37] [40], energy metabolism links to ATP supply pathways [41] [42], a nucleotide pool sanitizing enzyme protein which sanitizes oxidized dNTP pools to prevent incorporation of damaged bases produced by increased ROS in cancer cells [19] [43] [44]. Based on the preclinical success of both approaches, some metabolic inhibitors of these targets are now entering clinical trials (http://www.clinicaltrials.gov/) [37].

\section{Anticancer Drugs Developed from Anti-Tumor Immunity}

The development of human cancer is a multistep process characterized by the accumulation of genetic and epigenetic alterations that drive or reflect tumor progression. These changes distinguish cancer cells from their normal counterparts, allowing tumors to be recognized as foreign by the immune system. However, tumors are rarely rejected spontaneously, reflecting their ability to maintain an immunosuppressive microenvironment [45]-[47] which is now known as immune tolerance. Multiple mechanisms used by tumor cells, including alteration of the antigen presentation machinery or secretion of immunosuppressive factors that can induce apoptosis of lymphocytes or activate negative regulatory pathways, can induce immune tolerance and limit the effectiveness of the immune response [48]. Documented studies have demonstrated many cancer-induced cells, cytokines and molecules contribute to the development of immune tolerance, including regulatory $\mathrm{T}$ cells, myeloid-derived suppressor cells, tumorassociated macrophages and other suppressor lymphocyte subsets such as interleukin-10 producing B cells, B regulatory cells, cytokines such as interleukin-10, transforming growth factor-beta and colony stimulating factor 1 [45] [48]-[50]. In addition, programmed death-1 and cytotoxic $\mathrm{T}$ lymphocyte antigen- 4 are inhibitory receptors expressed on T cells or NK cells, and interactions with their ligands lead to inhibitory signal transduction of immune response. Immune tolerance hampers cytotoxic $\mathrm{T}$ lym- 
phocytes and natural killer cells from recognizing and eliminating tumor cells, stimulates tumor growth [50]-[54].

An effective antitumor immune response depends on breaking of immune tolerance which is the most exciting strategy for cancer immunotherapy. It requires processing of tumor-associated antigens by dendritic cells, presentation of antigens to antigen specific $\mathrm{T}$ cells, activation and proliferation of those $\mathrm{T}$ cells, and maintenance of the T-cell response long enough for the $\mathrm{T}$ cells to effectively eliminate the cancer. Effectiveness can result from activation at any point in this process. Cancer immunotherapy strategies designed to break tolerance can be broadly classified on the basis of the point in this process where the intervention takes place. Such strategies include adoptive transfer of immune effectors, vaccination, and immunomodulatory therapy. Adoptive transfer of immune effectors such as antitumor $\mathrm{mAb}$ and chimeric antigen receptor $\mathrm{T}$ cells bypasses many of the mechanisms involved in immune tolerance by allowing for expansion of tumor-specific effectors ex vivo. Vaccination with whole tumor cells, protein, peptide, or dendritic cells has proven challenging, yet may be more useful when combined with other cancer immunotherapeutic strategies. Immunomodulatory approaches to cancer immunotherapy include treatment with agents that enhance and maintain T-cell activation [38]. Many antibodies, cytokines, vaccines, and adoptive cell therapies are under development and some have been in the market, for example, ipilimumab and nivolumab are the latest and most potent monoclonal antibodies of cytotoxic T-lymphocyte antigen 4 and programmed death 1 expressed on $\mathrm{T}$ cells, respectively. Blocking those two inhibitory receptors keeps T cells active [48] [54]-[60]. Another example is the recent approval of the use of dinutuximab combination therapy for the treatment of high-risk neuroblastoma in paediatric patients. Dinutuximab is an IgG1 human/mouse chimeric switch variant of murine monoclonal antibody 14G2a, binds to a glycolipid found on the surface of tumour cells, which is overexpressed in neuroblastoma, and induces antibody-dependent cell-mediated cytotoxicity and complement-dependent cytotoxicity. The antibody by itself did not had a lot of activity against cancer, but once combined with IL-2, GM-CSF and 13-cis retinoic acid, its directed cellular cytotoxicity was greatly increased and a major increase in real cures was achieved [61].

\section{Perspectives}

In the past two decades, remarkable advances in basic science have led to new strategies for the treatment of cancer, which are justifiably generating optimism that it may soon be possible to cure a subset of patients with some types of cancer. Based on genomic sequencing of an individual's cancer cells, the mutations can then be targeted with compounds to block the downstream pathways that drive cancer development and progression and a more personalized treatment is achieved [62], further if combined with phenotype targeting drugs and/or immunotherapy, enormous effectiveness of cancer treatment has been observed; however the balance of risks and benefits for every combination has to be carefully evaluated in clinical trials because each therapy adds 
adverse effects [2] [63]. In addition, it is very worth mentioning that increasing evidence has shown that low dose radiation therapy/chemotherapy helps to break immune tolerance in patients with cancer and generate potent antitumor immune responses [64]-[67]. Thus if combination therapy is properly done, it seems likely that cures for many types of cancer will soon become reality.

\section{Conflict of Interest Statement}

The research was conducted in the absence of any commercial or financial relationships that could be construed as a potential conflict of interest.

\section{Acknowledgements}

The author Junjie $\mathrm{Xu}$ and Dr. Wenwei Mao thanks Dr. Stephen Creekmore and Dr. Dennis Michiel at Biopharmaceutical Development Program, Frederick National Laboratory for Cancer Research, NCI, NIH, Frederick, Maryland, USA for having Dr. Wenwei Mao as a visiting scholar during the writing of this manuscript and for helpful suggestion of modification of the manuscript.

\section{References}

[1] Mehta, K., Gandhi, V., Pathak, S., Aggarwal, B.B. and Grover, R.K. (2014) Multi-Targeted Approach to Cancer Treatment: An International Translational Cancer Research Symposium. Anticancer Research, 34, 6791-6795.

[2] Moffat, J.G., Rudolph, J. and Bailey, D. (2014) Phenotypic Screening in Cancer Drug Discovery-Past, Present and Future. Nature Reviews Drug Discovery, 13, 588-602. http://dx.doi.org/10.1038/nrd4366

[3] Adams, D.J. (2012) The Valley of Death in Anticancer Drug Development: A Reassessment. Trends in Pharmacological Sciences, 33, 173-180. http://dx.doi.org/10.1016/j.tips.2012.02.001

[4] Bailón-Moscoso, N., Romero-Benavides, J.C. and Ostrosky-Wegman, P. (2014) Development of Anticancer Drugs Based on the Hallmarks of Tumor Cells. Tumor Biology, 35, 3981-3995. http://dx.doi.org/10.1007/s13277-014-1649-y

[5] Widmer, N., Bardin, C., Chatelut, E., Paci, A., Beijnen, J., Levêque, D., et al. (2014) Review of Therapeutic Drug Monitoring of Anticancer Drugs Part Two-Targeted Therapies. European Journal of Cancer, 50, 2020-2036. http://dx.doi.org/10.1016/j.ejca.2014.04.015

[6] Lim, S.H. and Levy, R. (2014) Translational Medicine in Action: Anti-CD20 Therapy in Lymphoma. The Journal of Immunology, 193, 1519-1524. http://dx.doi.org/10.4049/jimmunol.1490027

[7] Brown, C. (2016) Targeted Therapy: An Elusive Cancer Target. Nature, 537, S106-S108. http://dx.doi.org/10.1038/537s106a

[8] Zhou, L., Xu, N., Sun, Y. and Liu, X.M. (2014) Targeted Biopharmaceuticals for Cancer Treatment. Cancer Letters, 352, 145-151. http://dx.doi.org/10.1016/j.canlet.2014.06.020

[9] Herviou, P., Thivat, E., Richard, D., Roche, L., Dohou, J., Pouget, M., Eschalier, A., Durando, X. and Authier, N. (2016) Therapeutic Drug Monitoring and Tyrosine Kinase Inhibitors. Oncology Letters, 12, 1223-1232.

[10] Obenauf, A.C., Zou, Y., Ji, A.L., Vanharanta, S.N, Shu, W., Shi, H., et al. (2015) Therapy-Induced Tumour Secretomes Promote Resistance and Tumour Progressio. Nature, 520, 


\section{8-372. http://dx.doi.org/10.1038/nature14336}

[11] Juric, D., Castel, P., Griffith, M., Griffith, O.L., Won, H.H. and Ellis, H. (2015) Convergent Loss of PTEN Leads to Clinical Resistance to a PI(3)Ka Inhibitor. Nature, 518, 240-244. http://dx.doi.org/10.1038/nature13948

[12] Lieu, C.H., Tan, A.C., Leong, S., Diamond, J.R. and Eckhardt, S.G. (2013) From Bench to Bedside: Lessons Learned in Translating Preclinical Studies in Cancer Drug Development. Journal of the National Cancer Institute, 105, 1441-1456. http://dx.doi.org/10.1093/jnci/djt209

[13] Ryall, K.A. and Tan, A.C. (2015) Systems Biology Approaches for Advancing the Discovery Of Effective Drug Combinations. Journal of Cheminformatics, 7, 7. http://dx.doi.org/10.1186/s13321-015-0055-9

[14] Martz, C.A., Ottina, K.A., Singleton, K.R., Jasper, J.S., Wardell, S.E., Peraza-Penton, A., et al. (2014) Systematic Identification of Signaling Pathways with Potential to Confer Anticancer Drug Resistance. Science Signaling, 7, ra121. http://dx.doi.org/10.1126/scisignal.aaa1877

[15] Crystal, A.S., Shaw, A.T., Sequist, L.V., Friboulet, L., Niederst, M.J., Lockerman, E.L., et al. (2014) Patient-Derived Models of Acquired Resistance Can Identify Effective Drug Combinations for Cancer. Science, 346, 1480-1486. http://dx.doi.org/10.1126/science.1254721

[16] Frangione, M.L., Lockhart, J.H., Morton, D.T., Pava, L.M. and Blanck, G. (2015) Anticipating Designer Drug-Resistant Cancer Cells. Drug Discovery Today, 20, 790-793. http://dx.doi.org/10.1016/j.drudis.2015.02.005

[17] Tong, L., Chuang, C.C., Wu, S. and Zuo, L. (2015) Reactive Oxygen Species in Redox Cancer Therapy. Cancer Letters, 367, 18-25. http://dx.doi.org/10.1016/j.canlet.2015.07.008

[18] Yang, W., Zou, L., Huang, C. and Lei, Y. (2014) Redox Regulation of Cancer Metastasis: Molecular Signaling and Therapeutic Opportunities. Drug Development Research, 75, 331341. http://dx.doi.org/10.1002/ddr.21216

[19] Gad, H., Koolmeister, T., Jemth, A.S., Eshtad, S., Jacques, S.A. and Ström, C.E. (2014) MTH1 Inhibition Eradicates Cancer by Preventing Sanitation of the dNTP Pool. Nature, 508, 215-222http://dx.doi.org/10.1038/nature13181

[20] Kawagishi, H. and Finkel, T. (2014) Unraveling the Truth about Antioxidants: ROS and Disease: Finding the Right Balance. Nature Medicine, 20, 711-713.

http://dx.doi.org/10.1038/nm.3625

[21] Sabharwal, S.S. and Schumacker, P.T. (2014) Mitochondrial ROS in Cancer: Initiators, Amplifiers or an Achilles' Heel? Nature Reviews Cancer, 14, 709-721. http://dx.doi.org/10.1038/nrc3803

[22] Ristow, M. (2014) Unraveling the Truth about Antioxidants: Mitohormesis Explains ROSInduced Health Benefits. Nature Medicine, 20, 709-711. http://dx.doi.org/10.1038/nm.3624

[23] Ibañez, I.L., Notcovich, C., Catalano, P.N., Bellino, M.G. and Durán, H. (2015) The Redox-Active Nanomaterial Toolbox for Cancer Therapy. Cancer Letters, 359, 9-19. http://dx.doi.org/10.1016/j.canlet.2015.01.013

[24] Lu, M., Lawrence, D.A., Marsters, S., Acosta-Alvear, D., Kimmig, P., Mendez, A.S., et al. (2014) Opposing Unfolded-Protein-Response Signals Converge on Death Receptor 5 to Control Apoptosis. Science, 345, 98-101. http://dx.doi.org/10.1126/science.1254312

[25] Wang, M. and Kaufman, R.J. (2014) The Impact of the Endoplasmic Reticulum Protein-Folding Environment on Cancer Development. Nature Review Cancer, 14, 581-597. http://dx.doi.org/10.1038/nrc3800 
[26] Hiramatsu, N., Chiang, W.C., Kurt, T.D., Sigurdson, C.J. and Lin, J.H. (2015) Multiple Mechanisms of Unfolded Protein Response-Induced Cell Death. American Journal of Pathology, 185, 1800-1808. http://dx.doi.org/10.1016/j.ajpath.2015.03.009

[27] Maas, N.L. and Diehl, J.A. (2015) Molecular Pathways: The PERKs and Pitfalls of Targeting the Unfolded Protein Response in Cancer. Clinical Cancer Research, 21, 675-679. http://dx.doi.org/10.1158/1078-0432.CCR-13-3239

[28] Lee, A.S. (2014) Glucose-Regulated Proteins in Cancer: Molecular Mechanisms and Therapeutic Potential. Nature Review Cancer, 14, 263-276. http://dx.doi.org/10.1038/nrc3701

[29] Tan, J.S., Ong, K.K.C. and Rhodes, A. (2016) The Role of Heat Shock Proteins and Glucose Regulated Proteins in Cancer. Malaysian Journal of Pathology, 38, 75-82.

[30] Brüning, A. and Jückstock, J. (2015) Misfolded Proteins: From Little Villains to Little Helpers in the Fight against Cancer. Frontiers in Oncology, 5, 47.

[31] Solárová, Z., Mojžiš, J. and Solár, P. (2015) Hsp90 Inhibitor as a Sensitizer of Cancer Cells to Different Therapies. International Journal of Oncology, 46, 907-926.

[32] Kukita, K., Tamura, Y., Tanaka, T., Kajiwara, T., Kutomi, G., Saito, K., et al. (2015) Cancer-Associated Oxidase ERO1- $\alpha$ Regulates the Expression of MHC Class I Molecule via Oxidative Folding. The Journal of Immunology, 194, 4988-4996.

http://dx.doi.org/10.4049/jimmunol.1303228

[33] Tanaka, T., Kajiwara, T., Torigoe, T., Okamoto, Y., Sato, N. and Tamura, Y. (2015) Cancer-Associated Oxidoreductase ERO1- $\alpha$ Drives the Production of Tumor-Promoting Myeloid-Derived Suppressor Cells via Oxidative Protein Folding. The Journal of Immunology, 194, 2004-2010. http://dx.doi.org/10.4049/jimmunol.1402538

[34] Delaunay-Moisan, A. and Appenzeller-Herzog, C. (2015) The Antioxidant Machinery of the Endoplasmic Reticulum: Protection and Signaling. Free Radical Biology \& Medicine, 83, 341-351. http://dx.doi.org/10.1016/j.freeradbiomed.2015.02.019

[35] Clarke, H.J., Chambers, J.E., Liniker, E. and Marciniak, S.J. (2014) Endoplasmic Reticulum Stress in Malignancy. Cancer Cell, 25, 563-573. http://dx.doi.org/10.1016/j.ccr.2014.03.015

[36] Hu, Z.Y., Xiao, L., Bode, A.M., Dong, Z. and Cao, Y. (2014) Glycolytic Genes in Cancer Cells Are More than Glucose Metabolic Regulators. Journal of Molecular Medicine, 92, 837-845. http://dx.doi.org/10.1007/s00109-014-1174-x

[37] Michels, J., Obrist, F., Castedo, M., Vitale, I. and Kroemer, G. (2014) PARP and Other Prospective Targets for Poisoning Cancer Cell Metabolism. Biochemical Pharmacology, 92, 164-171. http://dx.doi.org/10.1016/j.bcp.2014.08.026

[38] Augoff, K., Hryniewicz-Jankowska, A. and Tabola, R. (2015) Lactate Dehydrogenase 5: An Old Friend and a New Hope in the War on Cancer. Cancer Letters, 358, 1-7. http://dx.doi.org/10.1016/j.canlet.2014.12.035

[39] Fiume, L., Manerba, M., Vettraino, M. and Di Stefano, G. (2014) Inhibition of Lactate Dehydrogenase Activity as an Approach to Cancer Therapy. Future Medicinal Chemistry, 6, 429-445. http://dx.doi.org/10.4155/fmc.13.206

[40] Yélamos, J., Galindo, M., Navarro, J., Albanell, J., Rovira, A., Rojo, F. and Oliver, J. (2015) Enhancing Tumor-Targeting Monoclonal Antibodies Therapy by PARP Inhibitors. Oncoimmunology, 5, e1065370. http://dx.doi.org/10.1080/2162402X.2015.1065370

[41] Rodríguez-Enríquez, S., Gallardo-Pérez, J.C., Hernández-Reséndiz, I., Marín-Hernández, A., Pacheco-Velázquez, S.C., López-Ramírez, S.Y., et al. (2014) Canonical and New Generation Anticancer Drugs Also Target Energy Metabolism. Archives of Toxicology, 88, 1327 1350. http://dx.doi.org/10.1007/s00204-014-1246-2

[42] Bhat, T.A., Kumar, S., Chaudhary, A.K., Yadav, N. and Chandra, D. (2015) Restoration of 
Mitochondria Function as a Target for Cancer Therapy. Drug Discovery Today, 20, 635643. http://dx.doi.org/10.1016/j.drudis.2015.03.001

[43] Ji, D., Beharry, A.A., Ford, J.M. and Kool, E.T. (2016) A Chimeric ATP-Linked Nucleotide Enables Luminescence Signaling of Damage Surveillance by MTH1, a Cancer Target. Journal of the American Chemical Society, 138, 9005-9008. http://dx.doi.org/10.1021/jacs.6b02895

[44] Huber, K.V., Salah, E., Radic, B., Gridling, M., Elkins, J.M., Stukalov, A., et al. (2014) Stereospecific Targeting of MTH1 by (S)-Crizotinib as an Anticancer Strategy. Nature, 508, 222-227. http://dx.doi.org/10.1038/nature13194

[45] DuPage, M., Mazumdar, C., Schmidt, L.M., Cheung, A.F. and Jacks, T. (2012) Expression of tumour-Specific Antigens Underlies Cancer Immunoediting. Nature, 482, 405-409. http://dx.doi.org/10.1038/nature10803

[46] Teng, M.W., Galon, J., Fridman, W.H. and Smyth, M.J. (2015) From Mice to Humans: Developments in Cancer Immunoediting. Journal of Clinical Investigation, 125, 3338-3346. http://dx.doi.org/10.1172/JCI80004

[47] Kareva, I. and Berezovskaya, F. (2015) Cancer Immunoediting: A Process Driven by Metabolic Competition as a Predator-Prey-Shared Resource Type Model. Journal of Theoretical Biology, 380, 463-472. http://dx.doi.org/10.1016/j.jtbi.2015.06.007

[48] Makkouk, A. and Weiner, G.J. (2015) Cancer Immunotherapy and Breaking Immune Tolerance: New Approaches to an Old Challenge. Cancer Research, 75, 5-10. http://dx.doi.org/10.1158/0008-5472.CAN-14-2538

[49] Aranda, F., Vacchelli, E., Obrist, F., Eggermont, A., Galon, J., Sautès-Fridman, C., et al. (2014) Trial Watch: Toll-Like Receptor Agonists in Oncological Indications. Oncoimmunology, 3, e29179. http://dx.doi.org/10.4161/onci.29179

[50] Herbst, R.S., Soria, J.C., Kowanetz, M., Fine, G.D., Hamid, O., Gordon, M.S., et al. (2014) Predictive Correlates of Response to the Anti-PD-L1 Antibody MPDL3280A in Cancer Patients. Nature, 515, 563-567. http://dx.doi.org/10.1038/nature14011

[51] Aranda, F., Vacchelli, E., Eggermont, A., Galon, J., Sautès-Fridman, C., Tartour, E., et al. (2013) Trial Watch: Peptide Vaccines in Cancer Therapy. Oncoimmunology, 2, e26621. http://dx.doi.org/10.4161/onci.26621

[52] Pauken, K.E. and Wherry, E.J. (2014) TIGIT and CD226: Tipping the Balance between Costimulatory and Coinhibitory Molecules to Augment the Cancer Immunotherapy Toolkit. Cancer Cell, 26, 785-787. http://dx.doi.org/10.1016/j.ccell.2014.11.016

[53] Vacchelli, E., Aranda, F., Eggermont, A., Galon, J., Sautès-Fridman, C., Zitvogel, L., et al. (2014) Trial Watch: Tumor-Targeting Monoclonal Antibodies in Cancer Therapy. Oncoimmunology, 3, e27048. http://dx.doi.org/10.4161/onci.27048

[54] Zheng, Y., Dou, Y., Duan, L., Cong, C., Gao, A., Lai, Q., et al. (2015) Using Chemo-Drugs or Irradiation to Break Immune Tolerance and Facilitate Immunotherapy in Solid Cancer. Cellular Immunology, 294, 54-59. http://dx.doi.org/10.1016/j.cellimm.2015.02.003

[55] Gomez-Roca, C. and Delord, J.P. (2014) Emerging New Anticancer Therapies in 2013. Current Opinion in Oncology, 26, 357-362. http://dx.doi.org/10.1097/CCO.0000000000000081

[56] Ivanova, T.S., Krupodorova, T.A., Barshteyn, V.Y., Artamonova, A.B. and Shlyakhovenko, V.A. (2014) Anticancer Substances of Mushroom Origin. Experimental Oncology, 36, 5866.

[57] Powles, T., Eder, J.P., Fine, G.D., Braiteh, F.S., Loriot, Y., Cruz, C., et al. (2014) MPDL3280A (Anti-PD-L1) Treatment Leads to Clinical Activity in Metastatic Bladder 
Cancer. Nature, 515, 558-562. http://dx.doi.org/10.1038/nature13904

[58] Tumeh, P.C., Harview, C.L., Yearley, J.H., Shintaku, I.P., Taylor, E.J., Robert, L., et al. (2014) PD-1 Blockade Induces Responses by Inhibiting Adaptive Immune Resistance. Nature, 515, 568-571. http://dx.doi.org/10.1038/nature13954

[59] Naidoo, J., Page, D.B., Li, B.T., Connell, L.C., Schindler, K., Lacouture, M.E., Postow, M.A. and Wolchok, J.D. (2015) Toxicities of the Anti-PD-1 and Anti-PD-L1 Immune Checkpoint Antibodies. Annals of Oncology, 27, 1362. http://dx.doi.org/10.1093/annonc/mdw141

[60] Hoffman, R.M. and Zhao, M. (2014) Methods for the Development of Tumor-Targeting Bacteria. Expert Opinion on Drug Discovery, 9, 741-750. http://dx.doi.org/10.1517/17460441.2014.916270

[61] Dhillon, S. (2015) Dinutuximab: First Global Approval. Drugs, 75, 923-927. http://dx.doi.org/10.1007/s40265-015-0399-5

[62] Sharma, P. and Allison, J.P. (2015) The Future of Immune Checkpoint Therapy. Science, 348, 56-61. http://dx.doi.org/10.1126/science.aaa8172

[63] Shahabi, V., Postow, M.A., Tuck, D. and Wolchok, J.D. (2015) Immune-Priming of the Tumor Microenvironment by Radiotherapy: Rationale for Combination with Immunotherapy to Improve Anticancer Efficacy. American Journal of Clinical Oncology, 38, 90-97. http://dx.doi.org/10.1097/COC.0b013e3182868ec8

[64] André, N., Carré, M. and Pasquier, E. (2014) Metronomics: Towards Personalized Chemotherapy? Nature Reviews Clinical Oncology, 11, 413-431.

http://dx.doi.org/10.1038/nrclinonc.2014.89

[65] Demaria, S., Pilones, K.A., Vanpouille-Box, C., Golden, E.B. and Formenti, S.C. (2014) The Optimal Partnership of Radiation and Immunotherapy: From Preclinical Studies to Clinical Translation. Radiation Research, 182, 170-181. http://dx.doi.org/10.1667/RR13500.1

[66] Esposito, A., Criscitiello, C. and Curigliano, G. (2015) Immune Checkpoint Inhibitors with Radiotherapy and Locoregional Treatment: Synergism and Potential Clinical Implication. Current Opinion in Oncology, 27, 445-451. http://dx.doi.org/10.1097/CCO.0000000000000225

[67] Regal, J.F., Dornfeld, K.J. and Fleming, S.D. (2016) Radiotherapy: Killing with Complement. Annals of Translational Medicine, 4, 94. http://dx.doi.org/10.21037/atm.2015.12.46 
Submit or recommend next manuscript to SCIRP and we will provide best service for you:

Accepting pre-submission inquiries through Email, Facebook, LinkedIn, Twitter, etc.

A wide selection of journals (inclusive of 9 subjects, more than 200 journals)

Providing 24-hour high-quality service

User-friendly online submission system

Fair and swift peer-review system

Efficient typesetting and proofreading procedure

Display of the result of downloads and visits, as well as the number of cited articles

Maximum dissemination of your research work

Submit your manuscript at: http://papersubmission.scirp.org/

Or contact jet@scirp.org 